\title{
The two-speed genomes of filamentous pathogens: waltz with plants
}

\author{
Suomeng Dong ${ }^{1}$, Sylvain Raffaele ${ }^{2,3}$, and Sophien Kamoun ${ }^{4}$
}

Fungi and oomycetes include deep and diverse lineages of eukaryotic plant pathogens. The last 10 years have seen the sequencing of the genomes of a multitude of species of these so-called filamentous plant pathogens. Already, fundamental concepts have emerged. Filamentous plant pathogen genomes tend to harbor large repertoires of genes encoding virulence effectors that modulate host plant processes. Effector genes are not randomly distributed across the genomes but tend to be associated with compartments enriched in repetitive sequences and transposable elements. These findings have led to the "two-speed genome" model in which filamentous pathogen genomes have a bipartite architecture with gene sparse, repeat rich compartments serving as a cradle for adaptive evolution. Here, we review this concept and discuss how plant pathogens are great model systems to study evolutionary adaptations at multiple time scales. We will also introduce the next phase of research on this topic.

\section{Addresses}

${ }^{1}$ Department of Plant Pathology, Nanjing Agricultural University, Nanjing 210095, China

${ }^{2}$ INRA, Laboratoire des Interactions Plantes-Microorganismes (LIPM), UMR441, Castanet-Tolosan 31326, France

${ }^{3}$ CNRS, Laboratoire des Interactions Plantes-Microorganismes (LIPM), UMR2594, Castanet-Tolosan 31326, France

${ }^{4}$ The Sainsbury Laboratory, Norwich Research Park, Norwich NR4 7UH, United Kingdom

Corresponding author: Kamoun, Sophien (sophien.kamoun@tsl.ac.uk) 


\section{Introduction}

Infectious plant diseases wreak havoc to world agriculture and threaten renewed efforts to meet the food security needs of a booming world population. Among the most destructive plant pathogens are fungi and oomycetes, two groups of eukaryotes that are phylogenetically unrelated but exhibit similarities in their filamentous growth habit, heterotrophic lifestyle and specialized infection structures [1]. These so-called filamentous plant pathogens include notorious parasites, such as the rice blast fungus, several species of cereal-infecting rust fungi, the Irish potato famine pathogen, and many others that continue to trigger epidemics that threaten our food supply. Crop losses due to these filamentous pathogens amount to enough food to feed hundreds of millions of people [2]. Thus, it is not surprising that the plant pathology and genome biology communities teamed up to sequence the genomes of the main taxa of these formidable parasites. The first such genome, that of the rice blast fungus Magnaporthe oryzae, was reported only 10 years ago [3]. This was soon followed by the genomes of the oomycete soybean root rot pathogen Phytophthora sojae and the sudden oak death pathogen P. ramorum [4]. These landmark papers were accompanied by a flurry of publications with dozens of filamentous plant pathogen genomes becoming available for comparative analyses [5-12]. Interestingly, a number of concepts have emerged from comparative analyses of these genomes even though the species examined are highly diverse [13-19]. First, filamentous plant pathogen genomes tend to have distinctive architecture with an evolutionary trend towards large, repeat-bloated genomes. Second, these genomes harbor large repertoires of genes encoding secreted proteins, known as effector proteins, which function as virulence factors that modulate host plant processes. Finally, the effector genes are not randomly distributed across the genomes but tend to be associated with compartments enriched in repetitive sequences and transposable elements. These findings have led to the "two-speed genome" model in which pathogen genomes have a bipartite architecture with the gene sparse, repeat rich compartment serving as a cradle for adaptive evolution [5,17]. 
Remarkably, the unusual genome architecture and occurrence of effector genes in specific genome compartments is a feature that has evolved repeatedly in independent phylogenetic lineages of filamentous pathogens (Figure 1). This remarkable convergence in genome structure and its link to the pathogenic lifestyle of these organisms is a fundamental concept that has emerged from the last $\sim 10$ years of comparative genome analyses of fungal and oomycete pathogens. Here, we review this concept and discuss how plant pathogens are great model systems to study evolutionary adaptations at multiple time scales. We will also introduce the next phase of research on this topic.

\section{Genome size: bigger can be better}

The textbook view is that parasites and symbionts tend to evolve smaller and more compact genomes than their free-living relatives [20,21]. Filamentous plant pathogens include some of the most glaring exceptions to this notion [5]. Although not all species have expanded genomes, several lineages of filamentous plant pathogens are characterized by a proliferation of repetitive DNA and markedly increased genome size. The trend applies to independent and ancient parasite lineages, including the ascomycete powdery mildew fungi ( $\sim 120 \mathrm{Mbp}$., $64 \%$ repetitive for Blumeria graminis DH14) and bamboo witches' broom pathogen ( $\sim 60 \mathrm{Mbp} ., 57 \%$ repetitive for Aciculosporium take MAFF241224), basidiomycete rust fungi ( $220 \mathrm{Mbp}, 45 \%$ repetitive for Melampsora lini CH5), oomycetes of the genus Phytophthora ( 240 Mbp, 74\% repetitive for $P$. infestans T30-4) and downy mildews ( $\sim 100 \mathrm{Mbp}, 43 \%$ for Hyaloperonospora arabidopsidis Emoy2) [9,14,22-24]. In addition, several genomes, including those of the coffee rust and Asian soybean rust fungi, have not been fully sequenced yet because their large size and complexity have delayed these projects $[25,26]$. Convergence towards large genomes that are expanded compared to nonparasitic relatives is clearly an evolutionary trend in fungal and oomycete plant pathogens. But what are the evolutionary trade-offs of these repeat-bloated genomes? 


\section{Two-speed genomes: strikingly uneven rates of evolution across filamentous} pathogen genomes

A fundamental insight from analyses of filamentous plant pathogen genomes is that genes located in repeat-rich regions tend to evolve more rapidly than those in the rest of the genome $[5,17]$. This pattern could be demonstrated through comparative genomics of closely related species (Figure 2). Genome analyses of $P$. infestans and three of its sister species revealed uneven evolutionary rates across genomes with genes in repeat-rich regions showing higher rates of structural polymorphisms and positive selection [13]. A similar mosaic pattern was noted in the genome of the plant pathogenic fungus Leptosphaeria maculans $[15,16]$. Comparative genome analyses by Grandaubert et al. revealed that the expanded regions in the bipartite genome of Brassica infecting strains of L. maculans resulted from bursts of transposable element activity [16]. Genome analyses of the wheat fungal pathogen Zymoseptoria tritici and its closest known relatives also revealed a bipartite pattern of genome evolution with genes in essential and conditionally dispensable chromosomes evolving at strikingly different rates [27]. Comparison of complete genome sequences of 15 Clavicipitaceae fungi revealed frequent presence/absence polymorphisms and sequence variation in alkaloid biosynthesis gene clusters embedded in repeat-rich blocks [24,28]. These uneven patterns of genome evolution across filamentous pathogen genomes have led to the concept of "two-speed genome" with the gene sparse, repeat rich compartments serving as a cradle for adaptive evolution [5,17].

\section{Beyond comparative genomics: How does the two-speed genome accelerate pathogen evolution}

Initially, repeat-rich, gene poor genome compartments of filamentous pathogens were primarily thought of as hot spots for duplication, deletion, and recombination that result in accelerated evolution through increased structural variation. However, it is 
becoming clear that there are more mechanisms by which this particular genome architecture enables a faster tempo of pathogen evolution $[5,17,18,29]$. In some ascomycete fungi, close proximity of effector genes to degenerated transposable elements can result in increased levels of local mutagenesis through repeat-induced point (RIP) mutations. In both France and Australia, effector alleles of L. maculans with premature stop codons or non-synonymous RIP mutations have evolved to evade plant resistance mediated by the RLM immune receptors in just a few years [30-32]. Epigenetic silencing could also leak from TEs to neighboring genes thus disproportionally affecting genes in the repeat-rich regions of the genome [33-35]. Proximity to transposable elements may have enabled the persistence of the $M$. oryzae effector Avr-Pita in asexual populations of the rice blast fungus M. oryzae despite repeated adaptive deletions that generated genotypes virulent on rice plants carrying the Pi-ta resistance gene [36]. The occurrence of this "mobile effector" in different chromosomes of M. oryzae and related Pyricularia species is consistent with its lateral transfer through parasexual genetic exchange, a process that probably involves hitchhiking with a neighboring retrotransposon. Horizontal gene transfer can also be facilitated by accessory chromosomes, which are known to move laterally in fungi following hyphal anastomosis [19].

\section{Jump or die: convergence to the two-speed genome architecture might be driven by macroevolutionary dynamics}

Several oomycetes and fungi belong to deep lineages of plant pathogens. That they have engaged in uninterrupted antagonistic coevolutionary conflict with plants and yet managed to persist in the biota over millions of years is truly astonishing. The key to this evolutionary success is the ability of these fickle pathogens to overcome plant immunity, adapt to resistant plant varieties, and occasionally jump to new host species [5]. The distinct patterns of two-speed genome architecture identified in unrelated lineages of filamentous plant pathogens is intimately linked to the rapid evolutionary tempo of their effector genes and is, therefore, directly impacting their pathogenic 
lifestyle (Figure 2B). This remarkable convergence in genome architecture is best explained through the concept of clade selection. Lineages that evolved two-speed genomes have increased survivability - they are less likely to go extinct compared to lineages with less adaptable genomes, which are more likely to be purged out of the biota as their hosts develop full resistance or become extinct. In this "jump or die" model, pathogen lineages that have an increased likelihood to produce virulent genotypes on resistant hosts and non-hosts benefit from a macroevolutionary advantage and end up dominating the biota [5].

\section{Hidden in the genomes: diverse and large effector repertoires}

Genome sequencing of filamentous plant pathogen genomes has typically revealed large repertoires of (candidate) effector genes. This trend is particularly marked in oomycete pathogens. In Phytophthora, downy mildews, and Albugo spp. effector genes can be readily annotated in genome sequences because they contain signal peptides followed by conserved motifs, e.g. RXLR in Phytophthora and downy mildews [37]. The number of predicted effector genes is staggering. In the potato blight pathogen $P$. infestans, $\sim 550$ RXLR effector genes have been detected [23]. Another effector family, the Crinklers or CRNs, has also dramatically expanded in $P$. infestans to $\sim 200$ genes and $\sim 250$ pseudogenes [23]. Similar expanded secretomes have also been described in fungal plant pathogens. About 400-500 candidate secreted effector proteins (CSEPs) have been identified in the genomes of the barley and wheat powdery mildew fungus $B$. graminis $[6,7,14]$. In the rust fungi, up to 725 candidate effectors have been reported [9,38-40]. These effectors are thought to have a diversity of activities inside plant cells with several studies revealing that they target multiple host compartments and processes [41-44]. Effectors can also be metabolites that are coded by biosynthetic enzymes [45]. In Clavicipitaceae fungi, alkaloids generally serve as metabolite effectors produced by these plant-associated fungi to protect their host plants from predators [28]. Alkaloid biosynthesis loci are unstable due to 
surrounding large and pervasive blocks of repeats, thus increasing chemotypic variation of the alkaloids [24].

\section{The impact of host jumps on pathogen evolution}

Several filamentous plant pathogens have evolved by shifting or jumping from one host plant to another [46-48]. In some cases, the jumps are to plants that are distantly related to the ancestral host. Such events are expected to dramatically impact effector evolution considering that these proteins function inside a plant cellular environment and target plant molecules and processes (Figure 3). In case of host jumps to distant plant species, a subset of the effector repertoire may become obsolete because the effector target may not be absent in the new host. Indeed, effector gene deletion is rampant in the genome of the smut fungus $M$. pennsylvanicum, which is thought to have evolved from a grass pathogen into a dicot pathogen [49]. Similarly, an elevated rate of copy number variation was detected among effector genes of $P$. infestans and its sister species, which evolved by jumps to hosts from unrelated botanical families [13]. In other cases, effectors may adapt to a different target in the new host resulting in the accumulation of mutations that improve or expand the activity of the effector. Consistent with this model, a large number of effector and other in planta induced genes displays signatures of adaptive evolution among the Phytophthora clade 1c species $[13,50]$.

\section{Host adaptation and specialization as determinants of effector evolution}

Filamentous fungi and oomycetes provide striking examples of rapid evolutionary adaptations. These are particularly well documented for effectors that have a so-called “avirulence" (Avr) activity, namely that trigger receptor-mediated plant immunity $[51,52]$. Avr effector genes have evolved a variety of allelic variants to evade plant immunity. In some cases, these variants carry amino acid polymorphisms that evade activating host immunity while presumably preserving the effector's virulence 
activity. An example is the AVR-Pik gene of the rice blast fungus M. oryzae, which occurs as an allelic series with only a few amino acid polymorphisms that are mirrored by the matching resistance protein Pik-1 [53]. These polymorphisms appear to reflect arms race coevolutionary dynamics between $M$. oryzae and rice, with resistance responses correlating with binding of AVR-Pik to Pik-1 [53]. In other cases, gain of virulence was achieved through loss of function mutations such as premature stop codons or deletions [32,54]. Daverdin et al. monitored over four years the evolution of $L$. maculans populations faced with newly released oilseed rape cultivars with the $R \operatorname{lm} 7$ resistance gene [32]. L. maculans isolates virulent on $R \operatorname{lm} 7$ plants carried a diversity of independent molecular events in the matching effector gene AvrLm4-7, with RIP mutations and deletions the most frequent events [32]. Transcriptional silencing is yet another mechanism by which Avr effectors can evade host resistance $[35,55]$. Silencing of $P$. sojae effector gene $A v r 3 a$ enables this pathogen to gain virulence on soybean plants carrying the resistance gene Rps3 [33]. Silenced $A v r 3 a$ alleles were transmitted to progeny in non-Mendelian fashion and persisted over multiple generations suggesting that epigenetic changes at this locus mediated the gain of virulence phenotype [33].

Effectors can also adapt to their host target in order to better manipulate host defense. In one case, the biochemical basis of effector adaptation following a host jump could be resolved [50]. P. infestans cystatin-like effector EPIC1 and its ortholog from the sister species $P$. mirabilis PmEPIC1 are more effective inhibitors of proteases from their respective hosts, RCR3 from potato and MRP2 from Mirabilis jalapa, respectively [50]. A Gln to Arg substitution at position 111 in PmEPIC1, a derived mutation unique to the $P$. mirabilis lineage, increased MRP2 inhibition. However, this mutation carries a trade-off as it impairs the effector's ability to inhibit RCR3 proteases. This provides a molecular framework for effector specialization. An effector that evolved higher activity on a target in its new host performs poorly on the presumed ancestral host target. Evolution can therefore drive functional specialization 
of effectors during plant-pathogen coevolution, ultimately leading to the emergence and diversification of pathogen species [50].

\section{Outlook}

Pathogenomics of fungi and oomycetes is an emerging field of research in plant pathology. Many of these pathogens belong to deep lineages that have successfully engaged in antagonistic coevolution with plants over millions of years. Genome sequencing of unrelated taxa revealed a remarkable convergence in several independent lineages towards similar genome architectures with effector genes populating repeat-rich genome compartments. "Two-speed" genome architectures may have emerged as a successful solution to survivability of these pathogen lineages in the face of an ever-changing host environment [56]. Although more pathogen genomes need to be sequenced and analyzed, research is edging towards a mechanistic understanding of filamentous pathogen genome evolution. How two-speed genomes accelerate pathogen evolution and counteract lineage extinction is poised to be a key question for the next 10 years.

Plant pathogens are great model system to study rapid evolutionary adaptations. In many cases, particularly with regards to Avr effector-immune receptor dynamics, the genetic determinants and the nature of the adaptive mutations are known [see for example 57]. However, effector adaptation to host targets is not as well understood as coevolution with immune receptors. We need to gain a better view of the tempo of effector coevolution with host factors other than immune receptors.

We still know little about how pathogens and their effectors adapt and specialize on new hosts. We also need to understand better the determinants of host specificity. How do broad host range pathogens cope with their multiple hosts? How are their genomes shaped by their interactions with multiple hosts? An example of a genomics-driven insight is a recent study on the generalist parasite Albugo candida, 
which consists of multiple races that specialize on particular Brassicaceae species [58].

The genomes of host-specialized $A$. candida races display a mosaic architecture with evidence of genetic exchanges. Host immunosuppression by one $A$. candida race enables colonization by another race therefore explaining how genetic exchange could take place between specialized genotypes with non-overlapping host ranges. This led McMullan et al. to propose that the immunosuppression capacity of $A$. candida enables this species to maintain a wide host-range through occasional inter-race genetic exchanges and reassortment of effector gene repertoires [58]. Ultimately, this process enables $A$. candida populations to counteract the trade-offs associated with host-specialization and persist over long evolutionary times.

In conclusion, we need to capitalize on the conceptual advances in the field of plant-microbe interactions to expand our understanding of host-pathogen evolution. Future studies ought to combine comparative genomics analyses with mechanistic and biochemical studies of virulence in order to gain a thorough understanding of filamentous pathogen adaptation to their hosts across multiple evolutionary time scales.

\section{Acknowledgements}

We are thankful to past and present members of the Kamoun Lab as well as to several colleagues for numerous discussions and ideas. This review was developed based on reference [5] and was adapted from a talk available on YouTube (http://youtu.be/kogoAS_9Bgk). SD receives funding support from Chinese National Science Fund for Excellent Young Scholar (31422044). SR is supported by the European Research Council (ERC-StG 336808) and the Laboratory of Excellence project TULIP (ANR-10-LABX-41; ANR-11-IDEX-0002-02). SK receives funding primarily from the Gatsby Charitable Foundation, Biotechnology and Biological Sciences Research Council (BBSRC, UK), and European Research Council (ERC-NGRB). 
References and recommended reading

* of special interest

$* *$ of outstanding interest

1. Latijnhouwers M, de Wit PJ, Govers F: Oomycetes and fungi: similar weaponry to attack plants. Trends Microbiol 2003, 11:462-469.

2. Fisher MC, Henk DA, Briggs CJ, Brownstein JS, Madoff LC, McCraw SL, Gurr SJ: Emerging fungal threats to animal, plant and ecosystem health. Nature 2012, 484:186-194.

3. Dean RA, Talbot NJ, Ebbole DJ, Farman ML, Mitchell TK, Orbach MJ, Thon M, Kulkarni $\mathrm{R}, \mathrm{Xu} J \mathrm{R}, \mathrm{Pan} \mathrm{H}$, et al.: The genome sequence of the rice blast fungus Magnaporthe grisea. Nature 2005, 434:980-986.

4. Tyler BM, Tripathy S, Zhang X, Dehal P, Jiang RH, Aerts A, Arredondo FD, Baxter L, Bensasson D, Beynon JL, et al.: Phytophthora genome sequences uncover evolutionary origins and mechanisms of pathogenesis. Science 2006, 313:1261-1266.

5. Raffaele S, Kamoun S: Genome evolution in filamentous plant pathogens: why bigger can be better. Nat Rev Microbiol 2012, 10:417-430.

6. Wicker T, Oberhaensli S, Parlange F, Buchmann JP, Shatalina M, Roffler S, Ben-David R, Dolezel J, Simkova H, Schulze-Lefert P, et al.: The wheat powdery mildew genome shows the unique evolution of an obligate biotroph. Nat Genet 2013, 45:1092-1096.

7. Hacquard S, Kracher B, Maekawa T, Vernaldi S, Schulze-Lefert P, Ver Loren van Themaat E: Mosaic genome structure of the barley powdery mildew pathogen and conservation of transcriptional programs in divergent hosts. Proc Natl Acad Sci U S A 2013, 110:E2219-2228.

8. Hane JK, Anderson JP, Williams AH, Sperschneider J, Singh KB: Genome sequencing and comparative genomics of the broad host-range pathogen Rhizoctonia solani AG8. PLoS Genet 2014, 10:e1004281.

9. Nemri A, Saunders DG, Anderson C, Upadhyaya NM, Win J, Lawrence GJ, Jones DA, Kamoun S, Ellis JG, Dodds PN: The genome sequence and effector complement of the flax rust pathogen Melampsora lini. Front Plant Sci 2014, 5:98.

10. Porcel BM, Denoeud F, Opperdoes F, Noel B, Madoui MA, Hammarton TC, Field MC, Da Silva C, Couloux A, Poulain J, et al.: The streamlined genome of Phytomonas spp. relative to human pathogenic kinetoplastids reveals a parasite tailored for plants. PLoS Genet 2014, 10:e1004007.

11. Ohm RA, Feau N, Henrissat B, Schoch CL, Horwitz BA, Barry KW, Condon BJ, Copeland AC, Dhillon B, Glaser F, et al.: Diverse lifestyles and strategies of plant pathogenesis encoded in the genomes of eighteen Dothideomycetes fungi. PLoS Pathog 2012, 8:e1003037. 
12. Manning VA, Pandelova I, Dhillon B, Wilhelm LJ, Goodwin SB, Berlin AM, Figueroa M, Freitag M, Hane JK, Henrissat B, et al.: Comparative genomics of a plant-pathogenic fungus, Pyrenophora tritici-repentis, reveals transduplication and the impact of repeat elements on pathogenicity and population divergence. $G 3$ (Bethesda) 2013, 3:41-63.

13. Raffaele S, Farrer RA, Cano LM, Studholme DJ, MacLean D, Thines M, Jiang RH, Zody MC, Kunjeti SG, Donofrio NM, et al.: Genome evolution following host jumps in the Irish potato famine pathogen lineage. Science 2010, 330:1540-1543.

14. Spanu PD, Abbott JC, Amselem J, Burgis TA, Soanes DM, Stuber K, Ver Loren van Themaat E, Brown JK, Butcher SA, Gurr SJ, et al.: Genome expansion and gene loss in powdery mildew fungi reveal tradeoffs in extreme parasitism. Science 2010, 330:1543-1546.

15. Rouxel T, Grandaubert J, Hane JK, Hoede C, van de Wouw AP, Couloux A, Dominguez V, Anthouard V, Bally P, Bourras S, et al.: Effector diversification within compartments of the Leptosphaeria maculans genome affected by Repeat-Induced Point mutations. Nat Commun 2011, 2:202.

16. Grandaubert J, Lowe RG, Soyer JL, Schoch CL, Van de Wouw AP, Fudal I, Robbertse B, Lapalu N, Links MG, Ollivier B, et al.: Transposable element-assisted evolution and adaptation to host plant within the Leptosphaeria maculans-Leptosphaeria biglobosa species complex of fungal pathogens. BMC Genomics 2014, 15:891.

* This paper demonstrates that the L. maculans genome was recently invaded by transposable elements resulting in chromosomal rearrangements and the emergence of repeat-rich regions that harbor effector genes.

17. Croll D, McDonald BA: The accessory genome as a cradle for adaptive evolution in pathogens. PLoS Pathog 2012, 8:e1002608.

18. Stukenbrock EH, Croll D: The evolving fungal genome. Fungal Biology Reviews 2014, 28:1-12.

19. Ma LJ, van der Does HC, Borkovich KA, Coleman JJ, Daboussi MJ, Di Pietro A, Dufresne M, Freitag M, Grabherr M, Henrissat B, et al.: Comparative genomics reveals mobile pathogenicity chromosomes in Fusarium. Nature 2010, 464:367-373.

20. Keeling PJ: Reduction and compaction in the genome of the apicomplexan parasite Cryptosporidium parvum. Dev Cell 2004, 6:614-616.

21. McCutcheon JP, Moran NA: Extreme genome reduction in symbiotic bacteria. Nat Rev Microbiol 2012, 10:13-26.

22. Baxter L, Tripathy S, Ishaque N, Boot N, Cabral A, Kemen E, Thines M, Ah-Fong A, Anderson R, Badejoko W, et al.: Signatures of adaptation to obligate biotrophy in the Hyaloperonospora arabidopsidis genome. Science 2010, 330:1549-1551. 
23. Haas BJ, Kamoun S, Zody MC, Jiang RH, Handsaker RE, Cano LM, Grabherr M, Kodira CD, Raffaele S, Torto-Alalibo T, et al.: Genome sequence and analysis of the Irish potato famine pathogen Phytophthora infestans. Nature 2009, 461:393-398.

24. Schardl CL, Young CA, Hesse U, Amyotte SG, Andreeva K, Calie PJ, Fleetwood DJ, Haws DC, Moore N, Oeser B, et al.: Plant-symbiotic fungi as chemical engineers: multi-genome analysis of the clavicipitaceae reveals dynamics of alkaloid loci. PLoS Genet 2013, 9:e1003323.

25. Cristancho MA, Botero-Rozo DO, Giraldo W, Tabima J, Riano-Pachon DM, Escobar C, Rozo Y, Rivera LF, Duran A, Restrepo S, et al.: Annotation of a hybrid partial genome of the coffee rust (Hemileia vastatrix) contributes to the gene repertoire catalog of the Pucciniales. Front Plant Sci 2014, 5:594.

26. Loehrer M, Vogel A, Huettel B, Reinhardt R, Benes V, Duplessis S, Usadel B, Schaffrath U: On the current status of Phakopsora pachyrhizi genome sequencing. Front Plant Sci 2014, 5:377.

27. Stukenbrock EH, Jorgensen FG, Zala M, Hansen TT, McDonald BA, Schierup $\mathrm{MH}$ : Whole-genome and chromosome evolution associated with host adaptation and speciation of the wheat pathogen Mycosphaerella graminicola. PLoS Genet 2010, 6:e1001189.

28. Schardl CL, Florea S, Pan J, Nagabhyru P, Bec S, Calie PJ: The epichloae: alkaloid diversity and roles in symbiosis with grasses. Curr Opin Plant Biol 2013, 16:480-488.

29. Seidl MF, Thomma BP: Sex or no sex: evolutionary adaptation occurs regardless. Bioessays 2014, 36:335-345.

30. Fudal I, Ross S, Brun H, Besnard AL, Ermel M, Kuhn ML, Balesdent MH, Rouxel $\mathrm{T}$ : Repeat-induced point mutation (RIP) as an alternative mechanism of evolution toward virulence in Leptosphaeria maculans. Mol Plant Microbe Interact 2009, 22:932-941.

31. Van de Wouw AP, Cozijnsen AJ, Hane JK, Brunner PC, McDonald BA, Oliver RP, Howlett BJ: Evolution of linked avirulence effectors in Leptosphaeria maculans is affected by genomic environment and exposure to resistance genes in host plants. PLoS Pathog 2010, 6:e1001180.

32. Daverdin G, Rouxel T, Gout L, Aubertot JN, Fudal I, Meyer M, Parlange F, Carpezat J, Balesdent $\mathrm{MH}$ : Genome structure and reproductive behaviour influence the evolutionary potential of a fungal phytopathogen. PLoS Pathog 2012, 8:e1003020.

* A clear example of rapid allelic diversification of avirulence effector genes resulting in gain of virulence in natural populations of a plant pathogen.

33. Qutob D, Chapman BP, Gijzen M: Transgenerational gene silencing causes gain of virulence in a plant pathogen. Nat Commun 2013, 4:1349.

** A landmark paper on how a pathogen naturally evolves gain of virulence by epigenetically silencing an avirulence effector gene. The silenced state was associated with the appearance of 25-nucleotide small RNA molecules. 
34. Soyer JL, El Ghalid M, Glaser N, Ollivier B, Linglin J, Grandaubert J, Balesdent MH, Connolly LR, Freitag M, Rouxel T, et al.: Epigenetic control of effector gene expression in the plant pathogenic fungus Leptosphaeria maculans. PLoS Genet 2014, 10:e1004227.

** A pioneering mechanistic study on how epigenetic control, mediated by specific histone methytransferases, regulates the expression of virulence genes in a plant pathogen.

35. Gijzen M, Ishmael C, Shrestha SD: Epigenetic control of effectors in plant pathogens. Front Plant Sci 2014, 5:638.

36. Chuma I, Isobe C, Hotta Y, Ibaragi K, Futamata N, Kusaba M, Yoshida K, Terauchi R, Fujita Y, Nakayashiki H, et al.: Multiple translocation of the AVR-Pita effector gene among chromosomes of the rice blast fungus Magnaporthe oryzae and related species. PLoS Pathog 2011, 7:e1002147.

37. Pais M, Win J, Yoshida K, Etherington GJ, Cano LM, Raffaele S, Banfield MJ, Jones A, Kamoun S, Saunders DG: From pathogen genomes to host plant processes: the power of plant parasitic oomycetes. Genome Biol 2013, 14:211.

38. Duplessis S, Cuomo CA, Lin YC, Aerts A, Tisserant E, Veneault-Fourrey C, Joly DL, Hacquard S, Amselem J, Cantarel BL, et al.: Obligate biotrophy features unraveled by the genomic analysis of rust fungi. Proc Natl Acad Sci U S A 2011, 108:9166-9171.

39. Cantu D, Govindarajulu M, Kozik A, Wang M, Chen X, Kojima KK, Jurka J, Michelmore RW, Dubcovsky J: Next generation sequencing provides rapid access to the genome of Puccinia striiformis $\mathbf{f}$. sp. tritici, the causal agent of wheat stripe rust. PLoS One 2011, 6:e24230.

40. Zheng W, Huang L, Huang J, Wang X, Chen X, Zhao J, Guo J, Zhuang H, Qiu C, Liu J, et al.: High genome heterozygosity and endemic genetic recombination in the wheat stripe rust fungus. Nat Commun 2013, 4:2673.

41. Bozkurt TO, Schornack S, Banfield MJ, Kamoun S: Oomycetes, effectors, and all that jazz. Curr Opin Plant Biol 2012, 15:483-492.

42. Caillaud MC, Piquerez SJ, Fabro G, Steinbrenner J, Ishaque N, Beynon J, Jones JD: Subcellular localization of the Hpa RxLR effector repertoire identifies a tonoplast-associated protein HaRxL17 that confers enhanced plant susceptibility. Plant J 2012, 69:252-265.

43. Rafiqi M, Ellis JG, Ludowici VA, Hardham AR, Dodds PN: Challenges and progress towards understanding the role of effectors in plant-fungal interactions. Curr Opin Plant Biol 2012, 15:477-482.

44. Petre B, Saunders DG, Sklenar J, Lorrain C, Win J, Duplessis S, Kamoun S: Candidate Effector Proteins of the Rust Pathogen Melampsora larici-populina Target Diverse Plant Cell Compartments. Mol Plant Microbe Interact 2015, 28:689-700. 
45. Hogenhout SA, Van der Hoorn RA, Terauchi R, Kamoun S: Emerging concepts in effector biology of plant-associated organisms. Mol Plant Microbe Interact 2009, 22:115-122.

46. Roy BA: Patterns of association between crucifers and their flower-mimic pathogens: host jumps are more common than coevolution or cospeciation. Evolution 2001, 55:41-53.

47. Grunwald NJ, Flier WG: The biology of Phytophthora infestans at its center of origin. Annu Rev Phytopathol 2005, 43:171-190.

48. Thines M: Phylogeny and evolution of plant pathogenic oomycetes-a global overview. European Journal of Plant Pathology 2014, 138:431-447.

49. Sharma R, Mishra B, Runge F, Thines M: Gene loss rather than gene gain is associated with a host jump from monocots to dicots in the Smut Fungus Melanopsichium pennsylvanicum. Genome Biol Evol 2014, 6:2034-2049.

* This paper investigated the ecology and evolution of a smut fungus following a host jump. A high frequency of gene deletions appeared to be the hallmark of this pathogen adaptation to its new host.

50. Dong S, Stam R, Cano LM, Song J, Sklenar J, Yoshida K, Bozkurt TO, Oliva R, Liu $\mathrm{Z}$, Tian M, et al.: Effector specialization in a lineage of the Irish potato famine pathogen. Science 2014, 343:552-555.

** This study described the biochemical specialization of a plant pathogen effector following a host jump. A key amino-acid mutation largely explains adaptation and specialization of the pathogen effector.

51. Dodds PN, Rathjen JP: Plant immunity: towards an integrated view of plant-pathogen interactions. Nat Rev Genet 2010, 11:539-548.

52. Win J, Chaparro-Garcia A, Belhaj K, Saunders DG, Yoshida K, Dong S, Schornack S, Zipfel C, Robatzek S, Hogenhout SA, et al.: Effector biology of plant-associated organisms: concepts and perspectives. Cold Spring Harb Symp Quant Biol 2012, 77:235-247.

53. Kanzaki H, Yoshida K, Saitoh H, Fujisaki K, Hirabuchi A, Alaux L, Fournier E, Tharreau D, Terauchi R: Arms race co-evolution of Magnaporthe oryzae AVR-Pik and rice Pik genes driven by their physical interactions. Plant J 2012, 72:894-907.

* A clear example of a rapid arms race coevolution in both an Avr effector and matching immune receptor. The interaction is driven by direct binding of pathogen effector to host receptor.

54. Dong SM, Yin WX, Kong GH, Yang XY, Qutob D, Chen QH, Kale SD, Sui YY, Zhang ZG, Dou DL, et al.: Phytophthora sojae Avirulence Effector Avr3b is a Secreted NADH and ADP-ribose Pyrophosphorylase that Modulates Plant Immunity. Plos Pathogens 2011, 7.

55. Whisson S, Vetukuri R, Avrova A, Dixelius C: Can silencing of transposons contribute to variation in effector gene expression in Phytophthora infestans? Mob Genet Elements 2012, 2:110-114. 
56. Palmer ME, Feldman MW: Survivability is more fundamental than evolvability. PLoS One 2012, 7:e38025.

57. Vleeshouwers VG, Raffaele S, Vossen JH, Champouret N, Oliva R, Segretin ME, Rietman H, Cano LM, Lokossou A, Kessel G, et al.: Understanding and exploiting late blight resistance in the age of effectors. Annu Rev Phytopathol 2011, 49:507-531.

58. McMullan M, Gardiner A, Bailey K, Kemen E, Ward BJ, Cevik V, Robert-Seilaniantz A, Schultz-Larsen T, Balmuth A, Holub E, et al.: Evidence for suppression of immunity as a driver for genomic introgressions and host range expansion in races of Albugo candida, a generalist parasite. Elife 2015, 4.

** An elegant model to explain why Albugo candida, a plant parasite with broad host range, evolved the ability to suppress host immunity. Genome introgressions among races drive the exchange of effector repertoire, enabling natural populations to quickly adapt to distinct host species and persist as a generalist. 


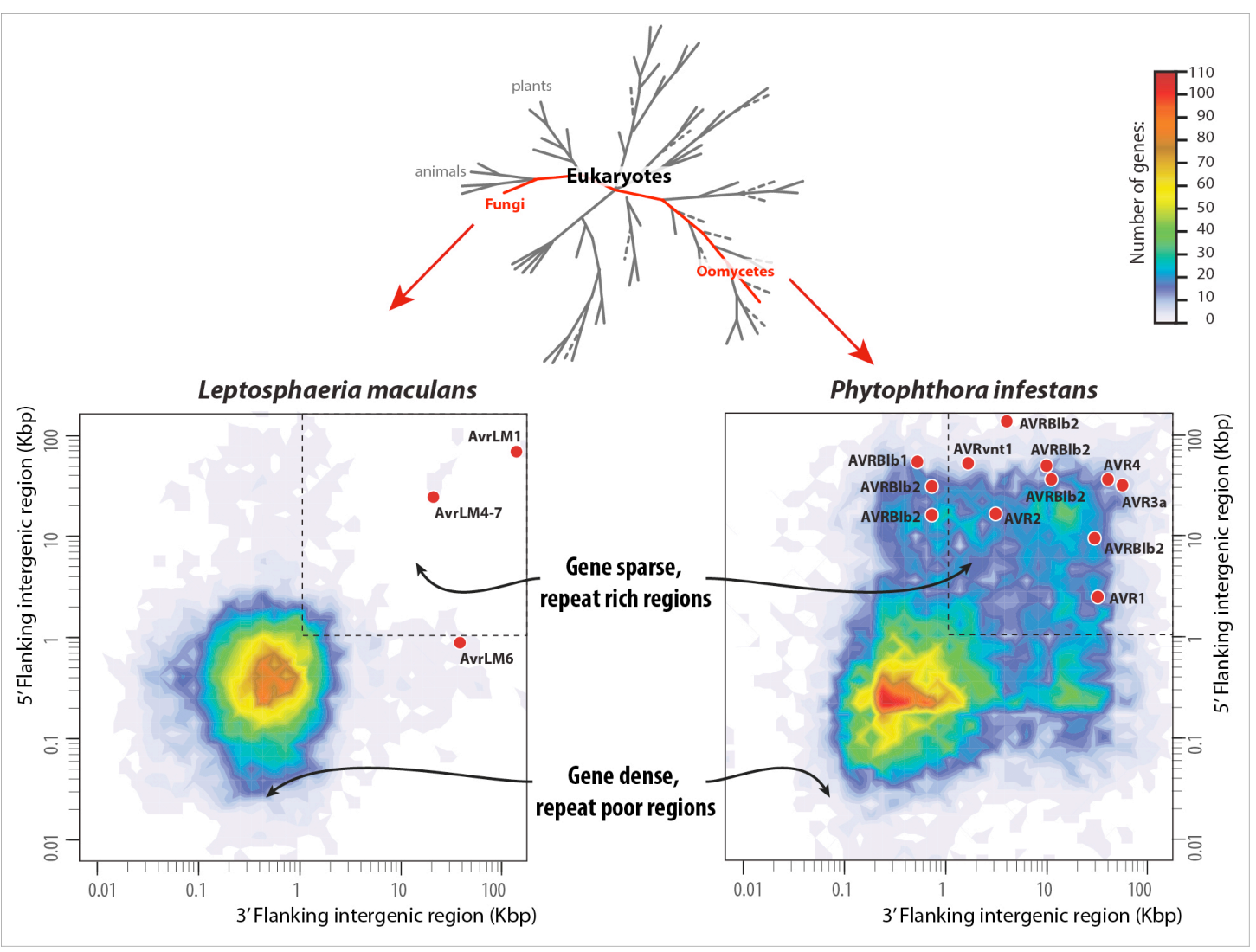

Figure 1. Convergence towards a similar genome architecture in phylogenetically unrelated plant pathogens. The flanking distance between neighbouring genes provides a measurement of local gene density and is displayed as a color-coded heat map based on a whole genome analysis of the fungus Leptosphaeria maculans and the oomycete Phytophthora infestans [23]. In addition, the figure displays the distribution of Avr effector genes of L. maculans and P. infestans according to the length of their 5' and 3' flanking intergenic regions. Note how in both cases the Avr effector genes primarily occupy the gene sparse regions of the genome. 


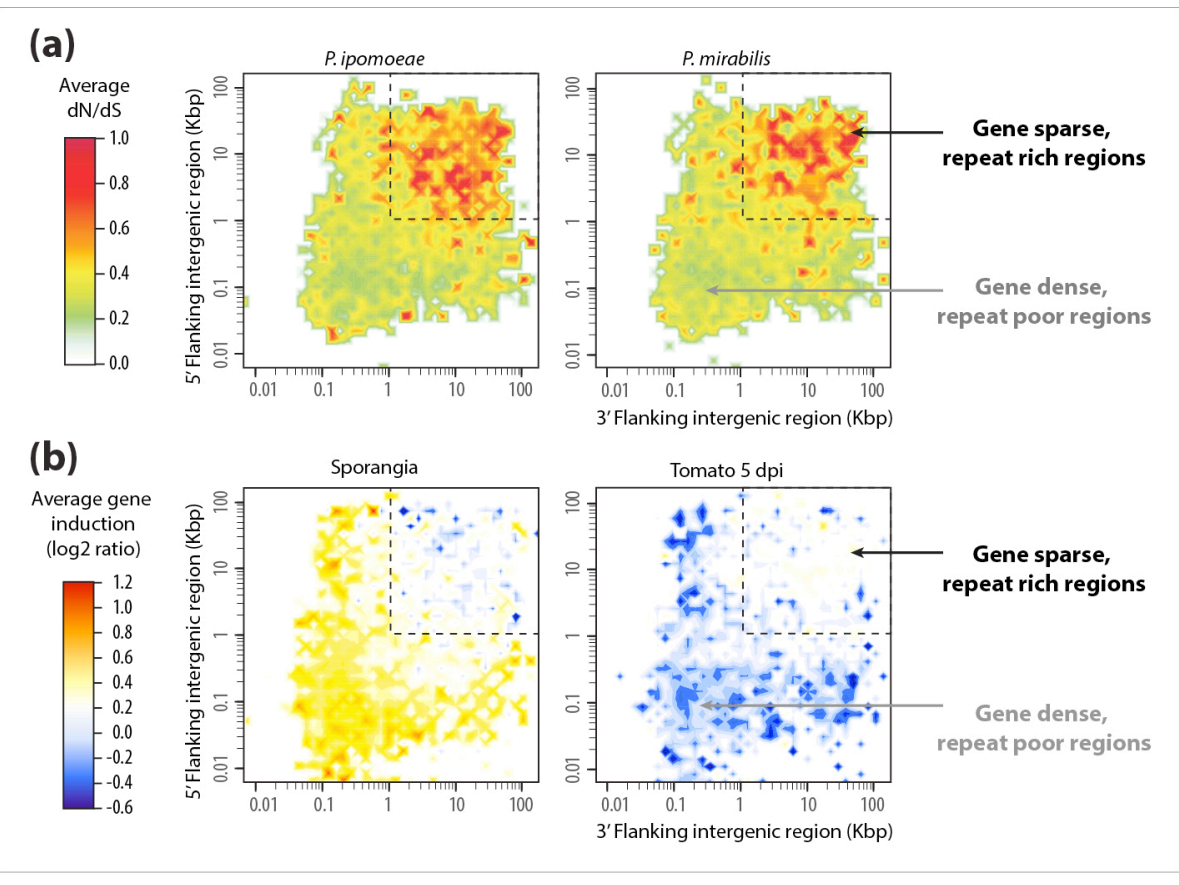

Figure 2. The two-speed genome of Phytophthora infestans. (a) Distribution of polymorphisms in $P$. ipomoeae and $P$. mirabilis according to local gene density (measured as length of 5' and 3' flanking intergenic regions) [13]. The average values of $\mathrm{dN} / \mathrm{dS}$ ratio (nonsynonymous to synonymous substitution rate) associated with genes in each bin are shown as a color-coded heat map. The ratios were calculated relative to $P$. infestans, the sister species of $P$. ipomoeae and $P$. mirabilis. Note that the gene-sparse regions are highly enriched in genes under positive selection with elevated dN/dS ratio. (b) Distribution of gene expression induction in sporangia and during infection of tomato 5 days post inoculation according to local gene density. The average induction values associated to genes in each bin are shown as a color-coded heat map. Note that genes that are induced in sporangia, which are the asexual spores of Phytophthora spp., are enriched in the gene-dense compartments of the genome, however, the gene-sparse regions of $P$. infestans genome are highly enriched in plant-induced genes. 


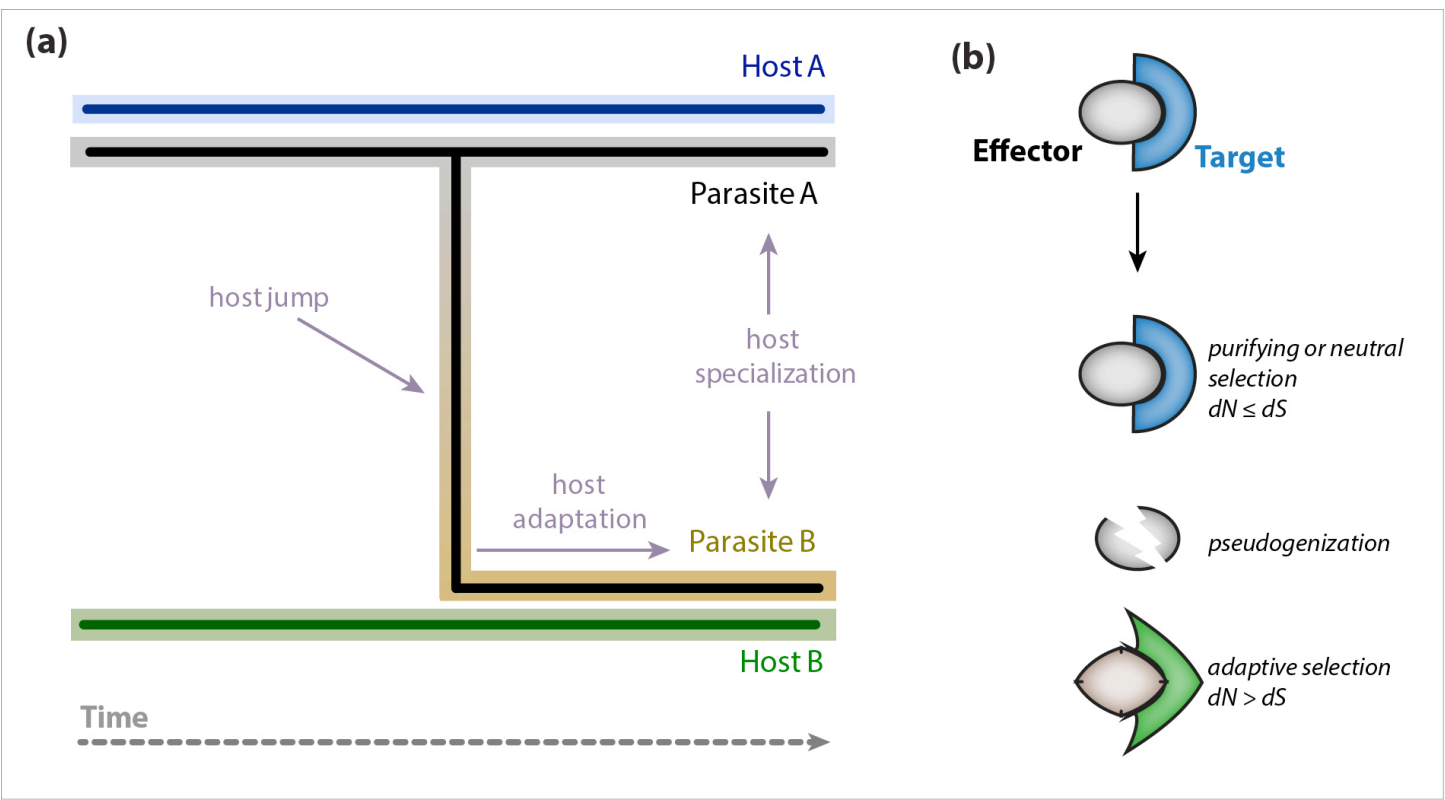

Figure 3. Impact of host jumps on effector evolution. (a) Schematic view of a hypothetical host jump of parasite A to host B followed by adaptation, specialization and eventually speciation of parasite B. The host jump is expected to have a dramatic effect on the effector repertoire of parasite $\mathrm{A}$ as effectors become exposed to a different host environment. The scheme in (b) depicts the three major scenarios of effector evolution following host jumps. We hypothesize that effector evolution in parasite B will be driven by the nature of the effector targets in the new host B. Panel (a) was adapted from Roy [46]. 